\title{
Predicting ADL disability in community-dwelling elderly people using physical frailty indicators: a systematic review
}

\author{
Joan Vermeulen ${ }^{1 * \dagger}$, Jacques CL Neyens ${ }^{1 \dagger}$, Erik van Rossum ${ }^{1,2+}$, Marieke D Spreeuwenberg ${ }^{1,2 \dagger}$ and \\ Luc $P$ de Witte ${ }^{1,2+}$
}

\begin{abstract}
Background: Disability in Activities of Daily Living (ADL) is an adverse outcome of frailty that places a burden on frail elderly people, care providers and the care system. Knowing which physical frailty indicators predict ADL disability is useful in identifying elderly people who might benefit from an intervention that prevents disability or increases functioning in daily life. The objective of this study was to systematically review the literature on the predictive value of physical frailty indicators on ADL disability in community-dwelling elderly people.

Methods: A systematic search was performed in 3 databases (PubMed, CINAHL, EMBASE) from January 1975 until April 2010. Prospective, longitudinal studies that assessed the predictive value of individual physical frailty indicators on ADL disability in community-dwelling elderly people aged 65 years and older were eligible for inclusion. Articles were reviewed by two independent reviewers who also assessed the quality of the included studies.

Results: After initial screening of 3081 titles, 360 abstracts were scrutinized, leaving 64 full text articles for final review. Eventually, 28 studies were included in the review. The methodological quality of these studies was rated by both reviewers on a scale from 0 to 27. All included studies were of high quality with a mean quality score of 22.5 (SD 1.6). Findings indicated that individual physical frailty indicators, such as weight loss, gait speed, grip strength, physical activity, balance, and lower extremity function are predictors of future ADL disability in community-dwelling elderly people.

Conclusions: This review shows that physical frailty indicators can predict ADL disability in community-dwelling elderly people. Slow gait speed and low physical activity/exercise seem to be the most powerful predictors followed by weight loss, lower extremity function, balance, muscle strength, and other indicators. These findings should be interpreted with caution because the data of the different studies could not be pooled due to large variations in operationalization of the indicators and ADL disability across the included studies. Nevertheless, our study suggests that monitoring physical frailty indicators in community-dwelling elderly people might be useful to identify elderly people who could benefit from disability prevention programs.
\end{abstract}

\section{Background}

In ageing Western societies, the prevalence of frailty and its adverse outcomes increases [1]. Disability in Activities of Daily Living (ADL), which are the essential activities that a person needs to perform to be able to live independently [2], is an adverse outcome of frailty

\footnotetext{
* Correspondence: j.vermeulen@maastrichtuniversity.nl

† Contributed equally

${ }^{1}$ School for Public Health and Primary Care (CAPHRI), Maastricht University, Maastricht, The Netherlands

Full list of author information is available at the end of the article
}

that places a high burden on frail individuals, care professionals and health care systems [3]. Frail elderly people have a higher risk of ADL disability compared to non-frail elderly people [4-6]. Effective interventions that prevent disability can diminish the burden caused by frailty. For the development of such interventions and the identification of people who might benefit from them, it is important to know which factors predict frailty-related ADL disability.

\section{Biomed Central}


Frailty is a concept that has been defined in many different ways [7-9]. Various physical, cognitive, psychological, nutritional and social factors have been claimed to contribute to frailty [10]. A definition of frailty that is often used by geriatricians is the following: 'a biologic syndrome of decreased reserve and resistance to stressors, resulting from cumulative decline across multiple physiologic systems, and causing vulnerability to adverse outcomes' [11]. The well known frailty phenotype by Fried et al. [12] which classifies people into categories of robust, pre-frail or frail fits within this physiologic approach of frailty. The frailty phenotype postulates that five indicators of physical functioning (unintentional weight loss, exhaustion, slow walking speed, low grip strength, and low physical activity) are related to each other in a cycle of frailty. A person with none of the indicators is robust, a person with 1 or 2 indicators is pre-frail, and a person with 3 or more indicators is frail. Elderly people who are frail according to the phenotype have a higher risk of disability [4-6].

Although evidence exists that the phenotype predicts disability, it always involves a combination of the five indicators and provides no insight into the predictive value of the individual indicators. Besides that, the phenotype does not provide insight into the predictive value of other possible indicators of physical functioning that might relate to frailty. If individual indicators can predict ADL disability this could be clinically useful in identifying elderly people who might benefit from an intervention that prevents disability or increases physical functioning in daily life. A systematic literature review was conducted to investigate this in community-dwelling elderly people.

\section{Methods}

\section{Search strategy}

Potentially relevant articles were obtained by performing a search in three databases (PubMed, CINAHL, and EMBASE) from January 1975 until April 2010. This cutoff point was chosen because the term frailty was first introduced around the 1980's. To specify the study population the MESH term "aged" was combined with terms such as "frail"", "vulnerable", "low functioning", or "community-dwelling" where "denotes truncated terms. To specify the physical frailty indicators terms such as "grip strength", "weight loss", "balance", "exhaustion", "walking speed", "gait", "physical activity", and related MESH terms were combined with OR. To specify the outcome measure terms such as "disabil"", "Activities of daily living", "functional decline", and related MESH terms were combined with OR. To specify the study design terms such as "cohort studies", "longitudinal", "prognos*", "predict*", and related MESH terms were combined with OR. The searches for study population, physical frailty indicators, outcome, and study design were combined with AND, resulting in the final search. Reference lists of selected reviews and studies were screened for relevant publications that were not identified in the original search. Relevant studies found in these reference lists that met all inclusion criteria were also included in the review.

\section{Study selection}

Articles were eligible for inclusion if they met the following inclusion criteria: 1) written in English or Dutch, 2) a prospective longitudinal design, 3) involving community-dwelling elderly people aged 65 years or older, 4) at least 1 physical frailty indicator as independent variable, and 5) ADL disability as outcome measure. Most recent studies on disability in elderly persons focus on the ability or difficulty in carrying out ADL [13]. The fact that people who suffer from ADL disability, cannot live independently justifies the use of this measure as a key outcome [2]. Articles with only mobility disability as outcome variable were not included because this does not reflect the much broader concept of ADL disability. Studies that only focused on elderly patients with a disease such as Parkinson, depression, or stroke were excluded from the review.

All retrieved articles were first reviewed by two independent reviewers (JV \& JCLN) based on their title. In case of disagreement or doubt, the article was included in the second phase of the selection process where all abstracts were assessed. Both reviewers independently labeled the remaining abstracts as 'include' or 'exclude'. Disagreement was resolved by consensus and if consensus could not be reached a third reviewer was consulted (MDS). In the third phase of the selection process, the full-text of the articles was retrieved and reviewed by both reviewers independently. Disagreement was resolved by consensus. In two cases the third reviewer had to be consulted. Agreement between the two independent reviewers in the second and third phase of the selection process was checked by calculating Cohen's Kappa.

\section{Quality assessment \& Data extraction}

The quality of the included articles was assessed by both reviewers independently using a list of 27 criteria (see Table 1). This list was constructed based on previous research on methodological quality, quality of reporting criteria for observational research, and previous reviews regarding prediction of disability [14-17]. Each item was scored with 0 or 1 resulting in a possible range of 0 to 27 points per included study. A higher score indicated higher quality.

Data regarding design, duration of follow up, sample size, population characteristics, physical frailty 
Table 1 List of quality criteria

\begin{tabular}{|c|c|c|c|}
\hline Nr. & Criteria & $\begin{array}{l}\text { Yes }= \\
1\end{array}$ & $\begin{array}{l}\text { No }= \\
0\end{array}$ \\
\hline 1 & Was the rationale of the research described? & & \\
\hline 2 & Were the objectives of the research clearly stated? & & \\
\hline 3 & Was the study a prospective cohort study? & & \\
\hline 4 & Was the follow-up of the cohort study 5 years or longer? & & \\
\hline 5 & Were the key-elements of the study design described? & & \\
\hline 6 & Were the setting, relevant dates and timeframe of the research described? & & \\
\hline 7 & Were the eligibility criteria for participants described? & & \\
\hline 8 & Were the participants free of disability at baseline? & & \\
\hline 9 & Were the predictors and dependent variables described? & & \\
\hline 10 & Were the measurement methods for the predictors and dependent variables described? & & \\
\hline 11 & Were standardized or valid measurements used for the predictors? & & \\
\hline 12 & Were standardized or valid measurements used for the outcome? & & \\
\hline 13 & Were potential types of bias addressed? & & \\
\hline 14 & Was it clear how the quantitative data were handled in the analyses? & & \\
\hline 15 & Were appropriate multivariate analysis techniques used? & & \\
\hline 16 & Did the statistical methods control for confounding and examine subgroups or interactions? & & \\
\hline 17 & Was there a description on how the final number of participants was established? & & \\
\hline 18 & Was the (loss to) follow-up of the participants described? & & \\
\hline 19 & Was the attrition less than $20 \%$ ? & & \\
\hline 20 & Was information provided regarding the baseline characteristics of participants? & & \\
\hline 21 & Was the number of outcome events or summary measures over time reported? & & \\
\hline 22 & $\begin{array}{l}\text { Were the results expressed in an Odds Ratio (OR), Risk Ratio (RR) or Hazard Ratio (HR) with the corresponding 95\% confidence } \\
\text { interval? }\end{array}$ & & \\
\hline 23 & If sub-group analyses were performed, were these clearly described? & & \\
\hline 24 & Were the key-results described in the discussion? & & \\
\hline 25 & Were the limitations of the study reported? & & \\
\hline 26 & $\begin{array}{l}\text { Were previous research and the limitations of the study taken into account when an overall interpretation of the study results } \\
\text { was provided? }\end{array}$ & & \\
\hline 27 & Was the generalisability of the study results described? & & \\
\hline
\end{tabular}

indicators, outcome measures and results were extracted from the included studies. The extracted data were not pooled due to the fact that there was a large heterogeneity in the way physical frailty indicators and ADL disability were measured. In order to draw conclusions on the predictive strength of the different indicators, the number of articles reporting a significantly increased risk of ADL disability were counted for each indicator. The number of studies was then split up into studies that only included participants who were free of disability at baseline and studies that included participants not free of disability at baseline. Higher weight was given to studies that only included participants free of disability at baseline $(++)$ compared to studies that included participants with and without disability at baseline $(+)$. Negative weight was given to studies that reported no significant predictive value of the studied indicator (-).
In some cases, two different studies that reported positive findings for the same indicator used data from the same cohort. This was taken into account in the interpretation of the results by counting these findings as one.

\section{Results}

\section{Selection process}

The search strategy yielded 3081 potentially relevant articles, after which 360 abstracts were scrutinized, leaving 64 full text publications for final review. After the selection process 28 studies were included in the review (see Figure 1 for details). The agreement between the two reviewers during the selection of abstracts and the selection of full-texts, as measured by Cohen's Kappa, was .74 and .82 respectively which is regarded as substantial to excellent. 
2721 articles excluded based on title because:

- Not meeting the inclusion criteria

- Duplicates

\section{0 potentially relevant articles}

\begin{tabular}{|l|l|l|}
\hline & $\begin{array}{l}296 \text { articles excluded based on abstract because: } \\
\text { - No longitudinal study }(57) \\
\text { - Not community-dwelling }(\mathrm{n}=6) \\
\text { - Aged younger than } 65 \text { years }(\mathrm{n}=36) \\
\text { - No individual physical indicators }(\mathrm{n}=42) \\
\text { - Outcome not ADL disability }(\mathrm{n}=116) \\
\text { - Specific group of elderly }(\mathrm{n}=17) \\
\text { - Duplicates ( }=3) \\
\text { - Other ( } \mathrm{n}=19)\end{array}$ \\
\hline
\end{tabular}

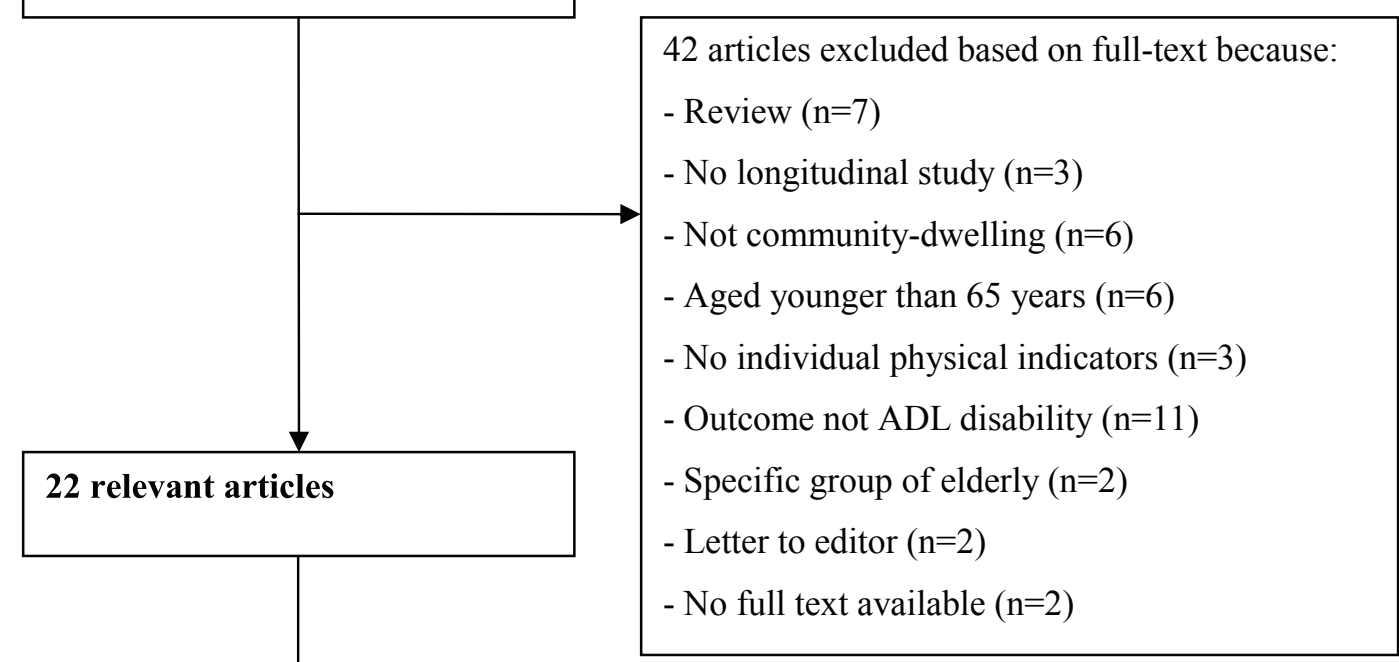

6 articles added from reference lists of retrieved reviews and included articles

28 articles included in review 


\section{Characteristics of included studies}

The characteristics and details of the 28 included studies are presented in Table 2, ordered by year of publication. The main results from the included studies are presented in Table 3. All included studies were longitudinal cohort studies. Various studies reported on the same cohort data: 5 studies were based on the (Hispanic) Established Population for the Epidemiological Study of the Elderly [18-22], 3 studies on the Precipitating Events
Project [23-25], 2 studies on the Jerusalem Longitudinal Study [26,27], 3 studies on the Longitudinal Interdisciplinary Study on Aging [28-30], 2 studies on the Cardiovascular Health Study [31,32], 2 studies on the Finland, Italy and The Netherlands Elderly Study [33,34], and 2 studies on the Project Safety cohort [35,36]. The other 9 included studies were based on other cohort studies [37-45]. The duration of follow-up of the studies varied from 1 year to 14 years (mean 5.4, SD 2.9 years). The

Table 2 Characteristics of included studies

\begin{tabular}{lll}
\hline $1^{\text {st }}$ Author (year) & Follow & Sample size \& Participant characteristics \\
& Up &
\end{tabular}

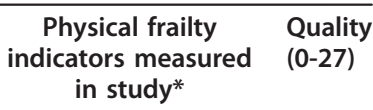

\begin{tabular}{|c|c|c|c|c|c|c|c|c|}
\hline Wu et al. (1999) [40] & 3 years & $\begin{array}{l}1321 \text { participants ( } 49 \% \text { women) } 44.4 \% \text { aged } 65-69 \text { and } 10.9 \% \text { aged } 80 \text { or } \\
\text { older }\end{array}$ & & & & $x$ & & 22 \\
\hline Guralnik et al. (2000) [19] & 6 years & 6534 participants aged 65 years and older & & $x$ & & & $x$ & 22 \\
\hline Ishizaki et al. (2000) [30] & 3 years & 583 participants (56\% women) with a mean age of 70.9 (SD 4.9) & & & $x$ & & & 23 \\
\hline Lee (2000) [38] & 7 years & 7527 men and women aged 70 years and older & & & & $x$ & & 20 \\
\hline Sarkisian et al. (2000) [39] & 4 years & 6632 women with a mean age of $73.0(4.9)$ & & $x$ & $x$ & $x$ & & 21 \\
\hline Shinkai et al. (2000) [29] & 6 years & 736 men and women aged 65 and older & & $x$ & $x$ & $x$ & $x$ & 24 \\
\hline $\begin{array}{l}\text { Stessman et al. (2002) } \\
\text { [27] }\end{array}$ & 7 years & 287 participants (51\% women) aged 70 years at baseline. & & & & $x$ & & 20 \\
\hline Wang et al. (2002) [45] & 3.4 years & 2578 participants (59\% women) aged 65 years and older & & & & $x$ & & 21 \\
\hline Shinkai et al. (2003) [28] & 6 years & 601 participants (56.1\% women) with a mean age of 70.9 (SD 4.9) & & $x$ & $x$ & $x$ & $x$ & 22 \\
\hline Al Snih et al. (2004) [22] & 7 years & 2493 participants (58\% women) with a mean age of 72 & & & $x$ & & & 24 \\
\hline Gill et al. (2004) [25] & 3 years & 754 participants (65\% women) aged 70 years or older & & $x$ & & & & 24 \\
\hline Al Snih et al. (2005) [21] & 7 years & 1737 Mexican- American participants (58\% women) aged 65 and older & $x$ & & & & & 23 \\
\hline $\begin{array}{l}\text { van den Brink et al. } \\
\text { (2005) [34] }\end{array}$ & 10 years & 560 men aged 70 to 89 years & & & & $x$ & & 26 \\
\hline Onder et al. (2005) [42] & 3 years & 884 women ( $72 \%$ white) with a mean age of 78.7 (SD 8.0) & & $x$ & $x$ & 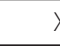 & $x \quad x$ & 23 \\
\hline Jacobs et al. (2008) [26] & 7 years & 343 men and women aged 70 years. & & & & $x$ & & 22 \\
\hline Ritchie et al. (2008) [43] & 4 years & 983 men and women with a mean age of 75.30 (SD 6.72) & $x$ & & & & & 22 \\
\hline Rosano et al. (2008) [31] & 8.4 years & $\begin{array}{l}3156 \text { participants ( } 57 \% \text { women, } 71 \% \text { white) with a mean age of } 74.0 \text { (SD } \\
\text { 4.6) }\end{array}$ & & $x$ & & & & 23 \\
\hline $\begin{array}{l}\text { Rothman et al. (2008) } \\
\text { [23] }\end{array}$ & 8 years & 754 men and women with a mean age of 78.4 (SD 5.3) & $x \quad x$ & $x$ & $x$ & $x$ & & 22 \\
\hline Gill et al. (2009) [24] & 9 years & 722 participants (65.2\% women) with a mean age of 78.4 (SD 5.2) & & & $x$ & & $x$ & 25 \\
\hline Arnold et al. (2010) [32] & 14 years & 3278 participants ( $61 \%$ women, $83 \%$ white) with a mean age of 80 & $x$ & & & & & 23 \\
\hline Balzi et al. (2010) [41] & 3 years & 897 Italian men and women, aged 65 to 102 & & & & $x$ & $x$ & 21 \\
\hline \multicolumn{3}{|c|}{ Total number of studies per indicator } & 41 & 12 & 10 & 96 & 68 & \\
\hline
\end{tabular}

* W: Weight loss, E: Exhaustion, G: Gait speed, M: Muscle strength, P: Physical activity, B: Balance, and O: Other indicators. 


\section{Table 3 Main results of included studies}

\begin{tabular}{|c|c|}
\hline $1^{\text {st }}$ Author (year) & Study Results \\
\hline Gill et al. (1995) [35] & $\begin{array}{l}\text { Each performance test (chair stand, rapid gait, } 360^{\circ} \text { turn, bending over, foot taps, and hand signature) is } \\
\text { significantly associated with the onset of functional dependence in ADL disability. Adjusted Risk Ratios (RR) vary } \\
\text { from } 1.2(.7-2.0) \text { for foot taps to } 2.4(1.4-4.2) \text { for rapid gait. }\end{array}$ \\
\hline Guralnik et al. (1995) [20] & $\begin{array}{l}\text { Elderly people with lowest lower extremity function have a higher risk of ADL disability compared to elderly } \\
\text { people in higher lower extremity function groups. RR 4.2 (2.3-7.7). Elderly people in the moderate group have a } \\
\text { higher risk of ADL disability compared to elderly people in the high group. RR } 1.6(1.0-2.6) \text {. }\end{array}$ \\
\hline Sonn et al. (1995) [37] & Walking speed and grip strength at age 70 are significantly associated with incident ADL disability at age 76. \\
\hline Tinetti et al. (1995) [44] & $\begin{array}{l}\text { Elderly people with lower usual gait speed, lower rapid gait speed, or lower balance have a higher risk of } \\
\text { functional dependence in ADL. OR } 2.0(1.5-2.7), 2.3(1.7-3.2) \text {, and } 2.0(1.5-2.7) \text { respectively. }\end{array}$ \\
\hline Gill et al. (1996) [36] & $\begin{array}{l}\text { Elderly people in the lowest quartile of physical function (measured by walking, turning, chair stands) have a } \\
\text { higher risk of functional dependence in ADL. RR } 2.1(1.4-3.0) \text {. }\end{array}$ \\
\hline Ostir et al. (1998) [18] & $\begin{array}{l}\text { Elderly people in the lowest quartile of walking speed, balance, and chair stands have a higher risk of ADL } \\
\text { disability after a 2-year follow-up compared to elderly people in the highest quartile. OR 5.4 (1.2-23.6), OR 2.4 } \\
\text { (1.0-5.4), and OR 2.8 (1.2-6.4) respectively. }\end{array}$ \\
\hline Giampaoli et al. (1999) [33] & $\begin{array}{l}\text { Elderly men with higher hand grip strength have a lower risk of disability compared to men with lower hand } \\
\text { grip strength. OR .97 (.96-.99). }\end{array}$ \\
\hline Wu et al. (1999) [40] & $\begin{array}{l}\text { Elderly people who participated regularly in exercise had a lower risk of becoming chronically ADL disabled } \\
\text { after a 3-year follow-up. RR .52 (.39-.68). }\end{array}$ \\
\hline Guralnik et al. (2000) [19] & $\begin{array}{l}\text { Elderly people with low lower extremity function have a higher risk of ADL disability compared to elderly } \\
\text { people with high lower extremity function. RR ranging from } 3.4(1.7-7.1) \text { to } 7.4(1.8-30.5) \text {. Elderly people with } \\
\text { moderate lower extremity function have a higher risk of ADL disability compared to elderly people with high } \\
\text { lower extremity function. RR ranging from } 1.2(.7-2.2) \text { to } 2.0(.7-5.3) \text {. Gait speed alone performed almost as well } \\
\text { as total lower extremity function in predicting incident disability. }\end{array}$ \\
\hline Ishizaki et al. (2000) [30] & $\begin{array}{l}\text { Elderly people with higher hand grip strength }(1 \mathrm{~kg}) \text { have a lower risk of developing disability in basic ADL } \\
\text { within the next } 3 \text { years. OR } .91(.84-.97) \text {. }\end{array}$ \\
\hline Lee (2000) [38] & $\begin{array}{l}\text { Elderly people who think that they are less active than other people their age have a higher risk of ADL } \\
\text { disability compared to people who think that they are a lot more active than other people their age. OR } 1.65 \\
(1.14-2.39) \text {. }\end{array}$ \\
\hline Sarkisian et al. (2000) [39] & $\begin{array}{l}\text { Elderly people in the lowest quintile of gait speed have a higher risk of decline in basic ADL. OR } 2.29 \text { (1.66- } \\
\text { 3.17). Elderly people in the lowest quintile of exercise level also have a higher risk of basic ADL decline. OR } 1.47 \\
(1.06-2.05) \text {. }\end{array}$ \\
\hline Shinkai et al. (2000) [29] & $\begin{array}{l}\text { Maximum walking speed, usual walking speed, balance, and grip strength are significant predictors of the } \\
\text { onset of functional ADL dependence after a } 6 \text {-year follow-up in elderly people who are aged } 65-74 \text { and } 75 \text { or } \\
\text { older. For elderly people in the lowest quartile the HR ranged from } 2.21 \text { (1.23-3.97) to } 6.18(3.16-12.1) \text {. }\end{array}$ \\
\hline Stessman et al. (2002) [27] & $\begin{array}{l}\text { Elderly people who are not physically active or who do not exercise at least four days a week at age } 70 \text { have a } \\
\text { higher risk of ADL disability after a 7-year follow- up compared to elderly people who are physically active at } \\
\text { age } 70 \text {. OR for men } 4.3(1.1-17.1) \text {, OR for women } 8.5 \text { (2.0-36.2). }\end{array}$ \\
\hline Wang et al. (2002) [45] & Elderly persons who exercise regularly have a decreased age-adjusted risk of functional decline in ADL. \\
\hline Shinkai et al. (2003) [28] & $\begin{array}{l}\text { Elderly people in the lowest quartile of hand grip strength, balance, usual walking speed or maximal walking } \\
\text { speed have a higher risk of disability in basic ADL. HR } 1.22 \text { (1.07-1.39), } 1.41 \text { (1.22-1.62), 1.31 (1.14-1.50), and 1.40 } \\
(1.22-1.61) \text { respectively. }\end{array}$ \\
\hline Al Snih et al. (2004) [22] & $\begin{array}{l}\text { Men and women in the lowest quartile of hand grip strength have a higher risk of ADL limitations in the next } \\
7 \text { years. HR for men } 1.9(1.14-3.17) \text { and HR for women } 2.28(1.59-3.27) \text {. }\end{array}$ \\
\hline Gill et al. (2004) [25] & Slow gait speed is associated significantly with the development of insidious disability. OR 2.4 (1.4-4.1). \\
\hline Al Snih et al. (2005) [21] & $\begin{array}{l}\text { Elderly people with weight loss of 5\% or more within a 2-year follow-up after baseline have a higher risk of } \\
\text { lower body ADL disability compared to elderly people with stable weight. Adjusted OR } 1.43 \text { (1.06-1.95). }\end{array}$ \\
\hline van den Brink et al. (2005) [34] & $\begin{array}{l}\text { Compared to the lowest tertile of total physical activity men from the middle and highest tertile have a lower } \\
\text { risk of disability. OR } .56(.32-99) \text { and OR .50 (.29- .88) respectively. }\end{array}$ \\
\hline Onder et al. (2005) [42] & $\begin{array}{l}\text { Balance, chair stands, and walking speed were significant predictors of progressive incident ADL disability. } \\
\text { Walking speed was also a significant predictor of catastrophic incident disability. }\end{array}$ \\
\hline Jacobs et al. (2008) [26] & $\begin{array}{l}\text { Elderly people who go out less then daily at age } 70 \text { have a higher risk of incident dependence in ADL } \\
\text { compared to elderly people who go out daily at age } 70 \text {. RR } 6.9(1.4-34.0) \text {. }\end{array}$ \\
\hline Ritchie et al. (2008) [43] & A history of unintentional weight loss at baseline predicts more rapid decline in ADL. \\
\hline Rosano et al. (2008) [31] & $\begin{array}{l}\text { Gait speed is a significant predictor of disability. HR .88 (.80-.96). This HR remains when controlling for age, sex, } \\
\text { race, education, and possible confounders. }\end{array}$ \\
\hline
\end{tabular}


Table 3 Main results of included studies (Continued)

\begin{tabular}{|c|c|}
\hline Rothman et al. (2008) [23] & $\begin{array}{l}\text { Slow gait speed, low physical activity and weight loss are significant predictors of chronic incident disability. HR } \\
3.0 \text { (2.3-3.8), HR } 2.1 \text { (1.7-2.6), and HR } 1.7(1.4-2.1) \text { respectively. Exhaustion and grip strength do not predict } \\
\text { chronic incident disability }\end{array}$ \\
\hline Gill et al. (2009) [24] & $\begin{array}{l}\text { Poor grip strength was associated with } 3 \text { subtypes of disability. OR ranging from } 1.42(1.03-1.95) \text { to } 1.80 \text { (1.04- } \\
\text { 3.12). Lower extremity performance score was significantly associated with } 5 \text { subtypes of ADL disability. OR } \\
\text { ranging from } 1.10(1.04-1.17) \text { to } 1.35(1.24-1.47) \text {. }\end{array}$ \\
\hline Arnold et al. (2010) [32] & $\begin{array}{l}\text { Elderly people with weight loss of } 5 \% \text { or more between consecutive annual visits have a higher risk of incident } \\
\text { ADL disability compared to elderly people with stable weight. Adjusted OR 1.27 (1.10-1.46). }\end{array}$ \\
\hline Balzi et al. (2010) [41] & $\begin{array}{l}\text { High level of physical activity compared to sedentary state is associated with a lower incidence of ADL } \\
\text { disability after a 3-year follow-up. OR .30 (.12-.76). Lower extremity performance score is a significant predictor } \\
\text { of disability. }\end{array}$ \\
\hline
\end{tabular}

sample size of the studies varied from 140 to 5727 (mean 1736, SD 2002). 75\% of the included studies were published between 1995 and 2005 .

The quality of the 28 included studies varied between 20 and 26 (27 was highest score possible). The mean quality score was high: 22.5 (SD 1.6) points. For each quality item, the Cohen's Kappa was calculated to measure the agreement between the two reviewers. The Kappas varied between 1.00 and .13. Agreement was high (Kappa > .70) for 18 items, moderate (Kappa between .40 and .70) for 7 items, and low (Kappa <.40) for 2 items. Of the included studies, $50 \%$ had a follow-up of 5 years or longer [19,21-24,26-29,31,32,34,37,38] and $68 \%$ included only participants who were free from disability at baseline [18-23,25,26,28-32,34-36,40-42]. Only $11 \%$ of the included studies did not use a standardized or valid measurement to measure the physical frailty indicators $[26,27,30]$ and only $4 \%$ did not use a standardized or valid measurement to measure ADL disability [38]. All studies used appropriate multivariate analysis and corrected for confounders in their analyses. $39 \%$ of the included studies had an attrition below $20 \%[19,20,24,25,29,34-36,40,42,44]$.

A variety of physical frailty indicators was measured in the included studies: weight loss, exhaustion, gait speed/ walking speed/gait, muscle strength/grip strength, physical activity, balance, lower extremity function, chair stand, $360^{\circ}$ turn, bending over, foot taps, and hand signature. There was considerable variation in the way the same indicators were measured and operationalized in different studies. Also, different cut-off points were used in different studies. More detailed information regarding the measurement of the indicators is presented in Additional file 1.

The operationalization of ADL disability also varied across studies. Some studies defined disability as dependency in ADL at follow-up, others as difficulty in ADL at follow-up, and some studies used chronic ADL disability as an outcome measure. Some studies only measured disability in 4 different ADL, whereas others measured disability in 5, 6, or 7 ADL. More detailed information regarding the measurement of ADL disability is also presented in Additional file 1.

\section{Predictive value of physical frailty indicators on ADL disability}

For each individual physical frailty indicator the evidence regarding the predictive value is described below. The information is summarized in Table 4.

\section{Weight loss}

Four studies provided information regarding the predictive value of weight loss on ADL disability. These four studies were based on separate cohorts that only included participants who were free of disability at baseline $[21,23,32,43]$. All four studies concluded that elderly people who report (unintentional) weight loss have a significant higher risk to develop ADL disability.

\section{Exhaustion}

Only one study reported on the predictive value of exhaustion on ADL disability [23]. This study concluded that feelings of exhaustion are not a significant predictor of ADL disability in elderly people.

\section{Gait speed}

Twelve studies provided information about the predictive value of gait speed (walking speed) as an individual physical frailty indicator on ADL disability $[18,19,23,25,28-30,35,37,39,42,44]$. All studies concluded that elderly people with slower gait speed have a higher risk of developing ADL disability. Nine studies were based on six separate cohort studies that only included participants free of ADL disability at baseline $[18,19,23,25,28,29,31,35,42]$. The other three studies were separate cohort studies that included participants with and without disability at baseline $[37,39,44]$.

\section{Muscle strength}

Ten studies provided information about the predictive value of muscle strength or hand grip strength on ADL disability [22-24,28-30,33,37,39,42]. Seven studies concluded that grip strength is a significant predictor of ADL disability [22,24,28-30,33,37]. Four studies, using data from two separate cohorts, only included participants free of ADL disability at baseline [22,28-30]. The other three separate cohort studies with a positive finding included participants with and without ADL disability at baseline $[24,33,37]$. Three studies concluded 
Table 4 Predictive strength of physical frailty indicators on ADL disability

\begin{tabular}{|c|c|c|c|c|}
\hline $\begin{array}{l}\text { Physical } \\
\text { frailty } \\
\text { indicator }\end{array}$ & $\begin{array}{l}\text { Total } \\
\text { number } \\
\text { of } \\
\text { studies }\end{array}$ & $\begin{array}{l}\text { Number of studies, only including } \\
\text { participants free of disability at } \\
\text { baseline, that reported a significant } \\
\text { increased risk of ADL disability } \\
\text { (Number of cohorts) } \\
++\end{array}$ & $\begin{array}{l}\text { Number of studies, including both } \\
\text { participants free and not free of ADL } \\
\text { disability at baseline, that reported a } \\
\text { significant increased risk of ADL } \\
\text { disability (Number of cohorts) } \\
+\end{array}$ & $\begin{array}{l}\text { Number of studies } \\
\text { reporting no significant } \\
\text { increased risk of ADL } \\
\text { disability (Number of } \\
\text { cohorts) } \\
\text { - }\end{array}$ \\
\hline Weight loss & 4 & $4(4)$ & $0(0)$ & $0(0)$ \\
\hline Exhaustion & 1 & $0(0)$ & $0(0)$ & $1(1)$ \\
\hline Gait speed & 12 & $9(6)$ & $3(3)$ & $0(0)$ \\
\hline $\begin{array}{l}\text { Muscle } \\
\text { strength }\end{array}$ & 10 & $4(2)$ & $3(3)$ & $3(3)$ \\
\hline $\begin{array}{l}\text { Physical } \\
\text { activity }\end{array}$ & 9 & $5(5)$ & $4(4)$ & $0(0)$ \\
\hline Balance & 6 & $4(3)$ & $1(1)$ & $1(1)$ \\
\hline \multicolumn{5}{|l|}{ Others: } \\
\hline $\begin{array}{l}\text { - Lower } \\
\text { extremity } \\
\text { function }\end{array}$ & 5 & $4(4)$ & $1(1)$ & $0(0)$ \\
\hline - Chair stands & 3 & $2(2)$ & $1(1)$ & $0(0)$ \\
\hline $\begin{array}{l}\text { - } 360^{\circ} \text { turn, } \\
\text { bending over, } \\
\text { foot taps, hand } \\
\text { signature }\end{array}$ & 1 & $1(1)$ & $0(0)$ & $0(0)$ \\
\hline
\end{tabular}

that grip strength is not a significant predictor of ADL disability $[23,39,42]$.

\section{Physical activity}

Nine studies reported on the predictive value of physical activity or exercise on ADL disability [23,26,27,34, 38-41,45]. All nine studies concluded that elderly people who are more physically active or who participate in exercise more regularly have a lower risk of developing ADL disability. Five out of these nine studies only included participants free of ADL disability at baseline $[23,26,34,40,41]$. These five studies were based on five separate cohort studies. The other four separate cohort studies included participants with and without disability at baseline $[27,38,39,45]$.

\section{Balance}

Six studies provided information about the predictive value of balance $[18,28,29,35,42,44]$. Five out of these six studies concluded that elderly people with poorer balance have a higher risk of developing ADL disability $[28,29,35,42,44]$. These five studies were based on three separate cohorts that only included participants free of ADL disability at baseline [28,29,35,42]. The other study with a positive finding included participants with and without ADL disability at baseline [44].

\section{Other physical frailty indicators}

Eight studies reported on the predictive value of physical frailty indicators that were not mentioned above namely: lower extremity function, chair stands, $360^{\circ}$ turn, bending over, foot taps, and hand signature.
Five of these studies reported on lower extremity function $[19,20,24,36,41]$. In all five studies, lower extremity function appeared to be a significant predictor of ADL disability. Elderly people with low lower extremity function had a higher risk of ADL disability at follow-up compared to people with moderate or high lower extremity function. Four of these studies were based on four separate cohorts that only included participants who were free of disability at baseline $[19,20,24,36]$. The other cohort study included participants with and without ADL disability at baseline [41].

Three studies investigated the predictive value of chair stands on ADL disability and concluded that this indicator is a significant predictor of ADL disability $[18,35,42]$. Two studies were based on two separate cohorts that only included participants who were free of disability at baseline $[18,35]$. The other cohort study included participants with and without ADL disability at baseline [42].

The study by Gill et al. [35] also investigated the predictive value of $360^{\circ}$ turn, bending over, foot taps, hand signature and concluded that all indicators were predictors for ADL disability. The cohort study only included participants who were free of disability at baseline.

\section{Discussion}

This review provides evidence that physical frailty indicators are predictors of ADL disability in communitydwelling elderly people aged 65 years and older. Elderly people with unintended weight loss, slower gait speed, 
lower grip strength, lower physical activity, lower exercise, poor balance, or low lower extremity function have a higher risk of ADL disability in the future. Apparently, physical frailty indicators do not only predict disability when they are related in a frailty phenotype [12] but also independent of each other.

The number of studies that focused on the predictive value on ADL disability differed per physical frailty indicator. Almost half of the included studies investigated the predictive value of gait speed whereas only one study reported on exhaustion. Besides that, there were large variations in the measurement of frailty indicators and ADL disability across the 28 included studies. Therefore, it is difficult to draw firm conclusions regarding the predictive power of the different indicators compared to each other. Nevertheless, taking into account the number of studies per indicator that suggested a significantly increased risk of ADL disability for this indicator provides some insight into the predictive value. Slow gait speed and low physical activity or exercise seem to have the highest predictive power, followed by weight loss, lower extremity function, balance, muscle strength, and other indicators. These findings should be interpreted with caution because pooling of the data from different studies was not possible.

The follow-up period of the cohorts varied across the included studies. Three studies had a follow-up of 1 or 2 years, six studies had a follow-up of 3 years, and the rest of the studies had a follow-up longer than 3 years. From this can be concluded that certain indicators predict disability in the short-term, long-term or both. For example, gait speed and balance predict the development of ADL disability after a follow up of one year $[35,44]$ and 6 years [29] and physical activity predicts the development of disability after a follow-up of 3 years $[40,41]$ and 10 years [34]. For the identification of elderly people who could benefit from an intervention that prevents ADL disability, it is more useful to know the 'short-term' predictive value of the physical frailty indicators. It makes more sense to start with a preventive intervention when 'short-term predictors' are present in elderly people compared to a situation in which it will take another 6 years (or longer) before disability will develop.

A large part of the included studies had a relatively long follow-up period. It would be interesting to see whether indicators that predict disability after a long period of time, are also predictors of disability on the short term, e.g. 1 year. Besides that, it would also be useful to know how much the functioning of the physical frailty indicators would have to decrease before disability starts to develop in elderly people. Many of the included studies used quartile or quintile scores to define high or low physical functioning in the frailty indicators. As a result, many of these studies reported limited generalisability of their findings. Clear cutoff points have not been established yet for all indicators. This could be a focus of future research and should also be taken into account when developing interventions that can prevent disability in community-dwelling elderly people.

The only physical frailty indicator that appeared not to predict ADL disability was exhaustion. However, only one study included in this review focused on this [23]. Exhaustion is a feeling not only related to physical functioning but also to mental/psychological functioning. Since the search strategy focused strongly on physical functioning, some studies regarding exhaustion might not have been retrieved. Another possibility might be that hardly any studies focusing on the predictive value of exhaustion have been conducted.

\section{Limitations of the review}

Despite the effort of the authors to conduct a sensitive search strategy, some relevant studies or unpublished articles may not have been retrieved. It is also very remarkable that almost all selected studies showed positive results and were of (very) high quality. This may indicate publication bias.

A remark must be made regarding the quality scores of the included studies which were quite high. This is not necessarily a limitation of the study but rather an exceptional finding. The high quality scores might have been caused by the selection criteria which allowed only prospective cohort studies to be included. Another possible explanation could be that the criteria that were used to assess the quality of the studies did not only refer to the methodological quality but also to the quality of reporting. This might have elevated the quality scores compared to when the quality of reporting criteria would not have been taken into account.

The term frailty was first introduced in the 1980's. If earlier studies used different definitions or measurement methods for frailty or its adverse outcomes compared to more recent studies, this might have introduced the possibility of time-lapse bias. However, the probability of this type of bias is probably small due to the broad search terms that were used in the search strategy.

Many studies that were included in the review were based on secondary data-analyses. If measurement of the indicators or ADL disability was not the primary aim of the study, this might have resulted in the use of suboptimal measurement methods. However, the quality assessment of the included articles revealed that the majority of the studies used standardized or validated measurements for the indicators and outcome variables. 


\section{Conclusions}

This review showed that physical frailty indicators predict ADL disability in community-dwelling elderly people. Slow gait speed and low physical activity/exercise seem to be the most powerful predictors followed by weight loss, lower extremity function, balance, muscle strength, and other indicators. Monitoring these indicators might be useful for identifying elderly people who could benefit from an intervention aimed at preventing ADL disability. Such an intervention could partly relieve the burden that frailty places on individuals, care providers and the health care system as a whole.

\section{Additional material}

Additional file 1: Measurement of physical frailty indicators and ADL disability. The table in Additional file 1 shows how physical frailty indicators and ADL disability were measured in the 28 included articles.

Acknowledgements and funding

Sponsor's role: Not applicable

\section{Author details}

'School for Public Health and Primary Care (CAPHRI), Maastricht University, Maastricht, The Netherlands. ${ }^{2}$ Research Centre Technology in Care, Zuyd University of Applied Sciences, Heerlen, The Netherlands.

\section{Authors' contributions}

JV contributed to the development of the search strategy, conducted the search, analyzed the articles ( $1^{\text {st }}$ reviewer), and drafted the manuscript. JCLN contributed to the development of the search strategy, analyzed the articles $\left(2^{\text {nd }}\right.$ reviewer), and helped to draft the manuscript. EvR contributed to the development of the search strategy and helped to draft the manuscript. MDS contributed to the development of the search strategy, was consulted during the in- and exclusion of articles ( $3^{\text {rd }}$ reviewer), and helped to draft the manuscript. LPdW was the project supervisor and contributed to conceptualization and development of the search strategy and helped to draft the manuscript

All authors read and approved the final manuscript.

\section{Competing interests}

The authors declare that they have no competing interests.

Received: 5 May 2011 Accepted: 1 July 2011 Published: 1 July 2011

\section{References}

1. Lally F, Crome P: Understanding frailty. Postgrad Med J 2007, 83:16-20.

2. Covinsky K: Aging, arthritis, and disability. Arthritis Rheum 2006, 55:175-176.

3. Rochat $\mathrm{S}$, Cumming RG, Blyth F, Creasey H, Handelsman D, Le Couteur DG, Naganathan V, Sambrook PN, Seibel MJ, Waite L: Frailty and use of health and community services by community-dwelling older men: the concord health and ageing in men project. Age Ageing 2010, 1:1-6.

4. Boyd CM, Xue QL, Simpson CF, Guralnik JM, Fried LP: Frailty, hospitalization, and progression of disability in a cohort of disabled older women. Am J Med 2005, 118:1225-31.

5. Al Snih S, Graham JE, Ray LA, Samper-Ternent R, Markides KS, Ottenbacher KJ: Frailty and incidence of activities of daily living disability among older merica mericans. J Rehabil Med 2009, 41:892-7.

6. Ensrud KE, Ewing SK, Cawthon PM, Fink HA, Taylor BC, Cauley J, Dam T, Marshall LM, Orwoll ES, Cummings SR: A comparison of frailty indexes for the prediction of falls, disability, fractures, and mortality in older men. J Am Geriatr Soc 2009, 57:492-8.
7. Morley JE, Perry HM, Miller DK: Something about frailty. J Gerontol A Biol Sci Med Sci 2002, 57A:698-704.

8. Markle-Reid M, Browne G: Conceptualizations of frailty in relation to older adults. J Adv Nurs 2003, 44:58-68.

9. Bergman H, Ferrucci L, Guralnik J, Hogan DB, Hummel S, Karunananthan S, Wolfson C: Frailty: an emerging research and clinical paradigm-issues and controversies. J Gerontol A Biol Sci Med Sci 2007, 62:731-7.

10. Levers MJ, Estabrooks CA, Ross Kerr JC: Factors contributing to frailty: literature review. J Adv Nurs 2006, 56:282-91.

11. Walston J, Hadley EC, Ferrucci L, Guralnik JM, Newman AB, Studenski SA, Ershler WB, Harris T, Fried LP: Research agenda for frailty in older adults: toward a better understanding of physiology and etiology: summary from the American Geriatrics Society/National Institute on Aging Research Conference on Frailty in Older Adults. J Am Geriatr Soc 2006, 54:991-1001

12. Fried LP, Tangen CM, Walston J, Newman AB, Hirsch C, Gottdiener J, Seeman T, Tracy R, Kop WJ, Burke G, McBurnie MA: Frailty in older adults: evidence for a phenotype. J Gerontol A Biol Sci Med Sci 2001, 56: M146-56.

13. Avlund K: Disability in old age. Longitudinal population-based studies of the disablement process. Dan Med Bull 2004, 51:315-349.

14. Altman DG: Systematic reviews of evaluations of prognostic variables. BMJ 2001, 323:224-228.

15. Stuck AE, Walthert JM, Nikolaus T, Büla CJ, Hohmann C, Beck JC: Risk factors for functional status decline in community-dwelling elderly people: a systematic literature review. Soc Sci \& Med 1999, 48:445-469.

16. Von Elm E, Altman DG, Egger M, Pocock SJ, Gotzsche PC, Vandenbroucke JP: The Strengthening the Reporting of Observational Studies in Epidemiology (STROBE) Statement: guidelines for Reporting observational studies. Plos Med 2007, 4:1623-1627.

17. Tas U, Verhagen AP, Bierma-Zeinstra SMA, Odding E, Koes BW: Prognostic factors of disability in older people: a systematic review. $\mathrm{Br} J$ of Gen Prac 2007, 57:319-323.

18. Ostir GV, Markides KS, Black SA, Goodwin JS: Lower body functioning as a predictor of subsequent disability among older Mexican Americans. J Gerontol A Biol Sci Med Sci 1998, 53:M491-5.

19. Guralnik JM, Ferrucci L, Pieper CF, Leveille SG, Markides KS, Ostir GV, Studenski S, Berkman LF, Wallace RB: Lower extremity function and subsequent disability: consistency across studies, predictive models, and value of gait speed alone compared with the short physical performance battery. J Gerontol A Biol Sci Med Sci 2000, 55:M221-31.

20. Guralnik JM, Ferrucci L, Simonsick EM, Salive ME, Wallace RB: Lowerextremity function in persons over the age of 70 years as a predictor of subsequent disability. N Engl J Med 1995, 332:556-61.

21. Al Snih S, Raji MA, Markides KS, Ottenbacher KJ, Goodwin JS: Weight change and lower body disability in older Mexican Americans. J Am Geriatr Soc 2005, 53:1730-7.

22. Al Snih S, Markides KS, Ottenbacher KJ, Raji MA: Hand grip strength and incident ADL disability in elderly Mexican Americans over a seven-year period. Aging Clin Exp Res 2004, 16:481-6.

23. Rothman MD, Leo-Summers L, Gill TM: Prognostic significance of potential frailty criteria. J Am Geriatr Soc 2008, 56:2211-116.

24. Gill TM, Murphy TE, Barry LC, Allore HG: Risk factors for disability subtypes in older persons. J Am Geriatr Soc 2009, 57:1850-5.

25. Gill TM, Allore H, Holford TR, Guo Z: The development of insidious disability in activities of daily living among community-living older persons. Am J Med 2004, 117:484-91.

26. Jacobs JM, Cohen A, Hammerman-Rozenberg R, Azoulay D, Maaravi $Y$, Stessman J: Going outdoors daily predicts long-term functional and health benefits among ambulatory older people. J Aging Health 2008, 20:259-72.

27. Stessman J, Hammerman-Rozenberg R, Maaravi Y, Cohen A: Effect of exercise on ease in performing activities of daily living from age 70 to 77: the Jerusalem Longitudinal Study. J Am Geriatr Soc 2002, 50:1934-1938.

28. Shinkai S, Kumagai S, Fujiwara Y, Amano H, Yoshida Y, Wanatabe S, Ishizaki T, Suzuki T, Shibata H: Predictors for the onset of functional decline among initially non-disabled older people living in a community during a 6-year follow-up. Geriatr \& Gerntol Intern 2003, 3:31-S39.

29. Shinkai S, Watanabe $S$, Kumagai S, Fujiwara $Y$, Amano H, Yoshida $H$, Ishizaki T, Yukawa H, Suzuki T, Shibata H: Walking speed as a good 
predictor for the onset of functional dependence in a Japanese rural community population. Age Ageing 2000, 29:441-6.

30. Ishizaki T, Watanabe S, Suzuki T, Shibata H, Haga H: Predictors for functional decline among nondisabled older Japanese living in a community during a 3-year follow-up. Am Geriatr Soc 2000, 48:1424-9.

31. Rosano C, Newman AB, Katz R, Hirsch CH, Kuller LH: Association between lower digit symbol substitution test score and slower gait and greater risk of mortality and of developing incident disability in well-functioning older adults. J Am Geriatr Soc 2008, 56:1618-25.

32. Arnold AM, Newman AB, Cushman M, Ding J, Kritchevsky S: Body weight dynamics and their association with physical function and mortality in older adults: the Cardiovascular Health Study. J Gerontol A Biol Sci Med Sci 2010, 65:63-70

33. Giampaoli S, Ferrucci L, Cecchi F, Lo Noce C, Poce A, Dima F, Santaquilani A, Vescio MF, Menotti A: Hand-grip strength predicts incident disability in non-disabled older men. Age \& Ageing 1999, 28:283-8.

34. Van Den Brink CL, Picavet H, Van Den Bos GA, Giampaoli S, Nissinen A, Kromhout D: Duration and intensity of physical activity and disability among European elderly men. Disabil Rehabil 2005, 27:341-7.

35. Gill TM, Williams CS, Tinetti ME: Assessing risk for the onset of functional dependence among older adults: the role of physical performance. J Am Geriatr Soc 1995, 43:603-9.

36. Gill TM, Williams CS, Richardson ED, Tinetti ME: Impairments in physical performance and cognitive status as predisposing factors for functional dependence among nondisabled older persons. J Gerontol A Biol Sci Med Sci 1996, 51A:M2830-M288.

37. Sonn U, Frandin K, Grimby G: Instrumental activities of daily living related to impairments and functional limitations in 70-year-olds and changes between 70 and 76 years of age. Scand J Rehabil Med 1995, 27:119-28.

38. Lee $Y$ : The predictive value of self assessed general, physical, and mental health on functional decline and mortality in older adults. J Epidemiol Community Health 2000, 54:123-9.

39. Sarkisian CA, Liu H, Gutierrez PR, Seeley DG, Cummings SR, Mangione CM: Modifiable risk factors predict functional decline among older women: a prospectively validated clinical prediction tool. The Study of Osteoporotic Fractures Research Group. J Am Geriatr Soc 2000, 48:170-8

40. Wu SC, Leu SY, Li CY: Incidence of and predictors for chronic disability in activities of daily living among older people in Taiwan. J Am Geriatr Soc 1999, 47:1082-6.

41. Balzi D, Lauretani F, Barchielli A, Ferrucci L, Bandinelli S, Buiatti E: Risk factors for disability in older persons over 3-year follow-up. Age \& Ageing 2010, 39:92-8.

42. Onder G, Penninx BW, Ferrucci L, Fried LP, Guralnik JM, Pahor M: Measures of physical performance and risk for progressive and catastrophic disability: results from the Women's Health and Aging Study. J Gerontol A Biol Sci Med Sci 2005, 60:74-9.

43. Ritchie CS, Locher JL, Roth DL, McVie T, Sawyer P, Allman R: Unintentional weight loss predicts decline in activities of daily living function and lifespace mobility over 4 years among community-dwelling older adults. J Gerontol A Biol Sci Med Sci 2008, 63:67-75.

44. Tinetti ME, Inouye SK, Gill TM, Doucette JT: Shared risk factors for falls, incontinence, and functional dependence. JAMA 1995, 273:1348-1353.

45. Wang L, Van Belle G, Kukull WB, Larson EB: Predictors of functional change: a longitudinal study of non-demented people aged 65 and older. J Am Geriatr Soc 2002, 50:1525-1534.

\section{Pre-publication history}

The pre-publication history for this paper can be accessed here: http://www.biomedcentral.com/1471-2318/11/33/prepub

doi:10.1186/1471-2318-11-33

Cite this article as: Vermeulen et al.: Predicting ADL disability in community-dwelling elderly people using physical frailty indicators: a systematic review. BMC Geriatrics 2011 11:33.

\section{Submit your next manuscript to BioMed Central and take full advantage of:}

- Convenient online submission

- Thorough peer review

- No space constraints or color figure charges

- Immediate publication on acceptance

- Inclusion in PubMed, CAS, Scopus and Google Scholar

- Research which is freely available for redistribution

Submit your manuscript at www.biomedcentral.com/submit
Biomed Central 